\title{
Developing a Model Based on Sustainable Development for Prioritizing Entrepreneurial Challenges Under a Competitive Environment
}

\author{
- Amir Khalilsanjani, Jonas Saparauskas, Abdolreza Yazdani-Chamzini, \\ Zenonas Turskis, Alireza Feyzbakhsh
}

\begin{abstract}
In the post-recession period, the business environment in developing countries is still relatively undesirable. Based on the reports published, the number of closed entrepreneurs are significantly more than the number of those newly established. These statistics also reflect that the development of entrepreneurship faces several challenges. However, a strategic management program must be accurately conducted to effectively control entrepreneurial challenges based on the limitation of time and financial resources. On the other hand, the program should provide an appropriate opportunity for competitiveness by producing better quality goods and services successfully marketed to consumers. The aim of this paper is to propose a robust model with a high potential for evaluation of entrepreneurial challenges in order to identify and control the most critical ones. To achieve the aim, the most critical parameters should be identified to prevent wasting the resources. Likewise, the analytical network process (ANP) method, a branch of multi-criteria decision making (MCDM) techniques, is a powerful tool that can consider all interrelationships and interdependencies between criteria. On the other hand, neutrosophic sets are among the most widespread approaches in coping with vagueness and unknown environment. The methodology employed in this paper uses a combination model based on ANP and neutrosophic sets using sustainable development indicators to prioritize the challenges of entrepreneurship. The results show that the proposed model has a high potential to provide a process for decision-making under a vague environment.
\end{abstract}

Keywords: competitiveness, neutrosophic sets, MCDM, ANP, sustainable development, entrepreneurial challenges

JEL Classification: Q01, L26, O11, Q56

Received: March, 2021 


\section{INTRODUCTION}

Over the last two decades, entrepreneurship and its impacts on the economy have been extensively investigated. The majority of researchers have found a significant impact of entrepreneurship on the economics. However, the research field continues to grow and develop (Neumann, 2020). The new environment of liberalization and globalization provides stimuli for entry and growth of entrepreneurial firms (Dixit et al., 2010). A professional skill for the successful entrepreneur is to solve novel problems in real-time by using experiences resulted from others. There is a burgeoning interest in entrepreneurial management. An entrepreneur should take into account different aspects of business activities, including (i) the awareness of the marketability of new technology or a product, (ii) the growth of firms to exploit business opportunities, and (iii) the capability to manage the enterprise from start to the maturity. In emerging markets, the novel environment of liberalization and globalization provides an appropriate opportunity for the growth and entry of entrepreneurial firms.

Over the last decade, the world has witnessed an unprecedented change in the technical and technological environment. The change means a substantial revolution in the way business is conducted. For example, some countries like Japan, Canada, Australia, the UK, and the USA adopted to liberalize their economies, therefore letting the markets overcome the controlling frameworks. However, most countries have conducted several scenarios based on the ability of an economy to achieve competitiveness by rising standards of living and high rates of employment on a sustainable basis. This may pose different opportunities for new firms to enter a particular product or service and the existing firms to enter a new business. However, these changes lead to increasing demand for firms to adapt themselves to sustainable development components in a dynamic manner, in which the behavior of firms changes timely based on the market requirements. To achieve the aim, firms focus on sustainable development indices to improve their position and attain rapid growth in the marketplace.

A typical firm faces challenges in competence learning, growing, and innovating as the new environment reflects an unknown situation. Therefore, the concentration of the firm's actions is to significantly respond to these challenges. While the topic of organizational performance has been meaningfully considered, the topic of entrepreneurial challenges has not been investigated comprehensively. A large number of studies have been on understanding the entrepreneurial process, but the studies about challenges are limited. Furthermore, the challenges are recognized in isolated conditions. On the other hand, using a set of rules makes it difficult to comprehensively manage a system because of the complexity of systems. Using a suitable decision process can lead to a reduction in decision failures. The ANP (analytic network process) method is a mathematical tool to deal with dependence and feedback (Saaty, 1996). The ANP technique is more adapted with real-world application than many conventional MCDM methods because of considering the dependence assumption among individual criteria.

An ANP-based decision analysis approach has many advantages: (1) it measures all tangible and intangible criteria in the modeling process, (2) it is a relatively simple and intuitive approach, (3) it can consider all independence, dependence, and inter-dependence relationships among the decision levels and attributes (Azimi et al., 2011; Fouladgar et al., 2012). However, the ANP method is criticized for its disability in formulating the inherent uncertainty involved in the 
decision process. On the other hand, neutrosophic set, an extension of fuzzy set, is known as a powerful approach in dealing with such situations. However, the relationships between the factors influencing entrepreneurial firms have not yet been elucidated, so that it is not clear which one is dominant in real situations. Therefore, the purpose of this study is to determine the impact of challenges on entrepreneurial firms based on sustainable indicators. This paper proposes an NANP model, a combination of neutrosophic set and ANP technique, to formulate both dependency and interdependency relationships under an uncertain environment.

This paper is structured as follows. The key challenges faced by an entrepreneurial firm based on a literature review are illustrated in the next section. The neutrosophic sets and their operators are presented in section 3 . In section 4 , the proposed model is clearly explained. In section 5, a real case is fulfilled and investigated. Finally, the results are comprehensively presented in the final section.

\section{THEORETICAL BACKGROUND}

\subsection{Literature survey}

According to the important role of entrepreneurial firms, different studies have been conducted to investigate the problem under consideration. Ragozzino \& Reuer (2010) expressed the challenges and opportunities of entrepreneurial firms. Lajqi \& Krasniqi (2017) investigated how entrepreneurs' employment growth aspirations are influenced by social capital, human capital, and institutional quality. Dixit et al. (2010) described how the new environment of globalization, deregulation and liberalization creates several challenges for entrepreneurial firms. The influence of the major problems and restrictions on the development of the entrepreneurial sector in Serbia is analyzed by Stefanovic et al. (2013). An exploratory assessment model to gain the major factors that affect the success of international entrepreneurial projects is proposed by Brière et al. (2015). Rae (2017) explored the emerging contribution of leadership development to sustainable entrepreneurship. Taylor (2021) utilized two case studies to present widely divergent forms of entrepreneurship. Rajagopal (2021) showed entrepreneurial challenges could influence psychological, economic, social, and geo-demographic factors.

Welter \& Smallbone (2011) examined the institutional embeddedness of entrepreneurial behavior. Wonglimpiyarat (2015) developed qualitative research using case study methodology by focusing on the policy perspectives of bank financing to analyze the small and medium-sized enterprises in the case of China. Cantele \& Vernizzi (2015) demonstrated that entrepreneurial challenges play a role in the overall value creation process. Gelard \& Saleh (2011) proposed a model for selecting the best entrepreneur using the evaluation criteria extracted from the challenging parameters. Li et al. (2019) demonstrated entrepreneurial firms with religious owners invest more in social responsibility. Bahl et al. (2021) examined the relationship in the context of entrepreneurial firms in transition economies. Bai et al. (2020) explored the role of internal social exchanges in contributing to the international performance of young entrepreneurial firms. Matricano (2020) investigated the impact of entrepreneurship trajectories on the performance of entrepreneurial firms. Jiang et al. (2018) indicated green entrepreneurial orientation has positive influences on both environmental and financial performance. 
On the other hand, based on the potential application of the neutrosophic set, different researchers have employed it to formulate the problem under consideration. Broumi et al. (2014) presented neutrosophic parameterized soft set and its operations. An extended TOPSIS method for a multiple attribute group decision-making problem based on single-valued neutrosophic sets was developed by Ye (2015). Biswas et al. (2016) used single-valued neutrosophic sets to develop the TOPSIS method for group decision-making. Peng et al. (2016) developed a novel qualitative flexible multiple criteria method based on neutrosophic sets. An optimized method of PROMETHEE on the base of neutrosophic sets is developed by Wang \& Liu (2016).

Garg \& Nancy (2017) utilized interval neutrosophic numbers to introduce a nonlinear programming model. Zhang et al. (2016) used a novel outranking approach based on a neutrosophic set to solve an MCDM problem. Baušys \& Juodagalviene (2017) solved a location selection problem by combining WASPAS model with neutrosophic sets. Hu et al. (2017) used the VIKOR method and interval neutrosophic sets to measure a projection-based difference. Jiang \& Shou (2017) measured the similarity between neutrosophic sets by using DempsterShafer's evidence theory. Li et al. (2019) used neutrosophic sets to incorporate the evaluation based on distance from the average solution method with power aggregation operators. A model based on a neutrosophic set is developed by Khatter (2021) to solve an MCDM problem. Liang et al. (2017) proposed an integrated model based on decision-making trial and evaluation laboratory (DEMATEL) and the single-valued trapezoidal neutrosophic to analyze the causal relationships among criteria. Peng \& Smarandache (2020) measured multiparametric similarity with combination weight by using neutrosophic sets. Thong et al. (2020) proposed an extended TOPSIS method with unknown weight information in a dynamic neutrosophic environment. Abdel-Basset et al. (2020) utilized trapezoidal neutrosophic numbers to estimate the activities durations in project management. Wang \& Zhang (2017) used the TODIM method with the probability multivalued linguistic neutrosophic sets.

\subsection{Sustainability}

Sustainability is a term used to connect development to the environment. Over the recent decades, an attempt has been made to simultaneously consider the concept of all aspects of development. The World Commission on Environment and Development (WCED) firstly discussed sustainable development as development that "meets the needs of the present without compromising the ability of future generations to meet their own needs" (Rogers et al., 2008). Sustainable development is can be defined as a function of three components, including economic, environmental, and social parameters. The first parameter indicates a maximum income or an increase in capital. The second reflects the resilience and robustness of biological and physical systems. The last indicates the stability of social and cultural systems. Based on the statistical data reported by the United Nations Development Programme (UNDP), the wealthiest 20\% of the global population earns $82.7 \%$ of the total global income (Rogers et al., 2008). This income distribution reflects an unbalanced situation. Therefore, sustainable development provides a systemic approach to integrate different aspects into a comprehensive model in order to build a meaningful relationship among different criteria. The primary goal of sustainable development is to increase the sustainable competitiveness of economies, social and environmental problems. 
In recent years, sustainable development has received considerable attention from different researchers to integrate environmental, economic, and social concerns in science and management (Xu et al., 2019; Nousheen et al., 2020; Shafieisabet \& Haratifard, 2020; Yuan \& Lo, 2020; Shulla et al., 2020; Laurett et al., 2021). Nguyen (2020) investigated the impact of sustainability on firm value. In this study, a significant negative relation between firm value and sustainability reporting has resulted. Mashokhida et al. (2018) used the method of com $\neg$ parative analysis to assess the level of competitiveness of the Tajikistan regions to sustainability determine their economic development. Ginevicius (2019) proposed a methodology to quantitatively evaluate the sustainability of the country's region's development. Therefore, it is necessary to develop an effective framework to provide a systematic approach for balancing social, environmental, and economic concerns in order to identify key sustainability issues, determine actions and solutions, enable performance measuring, evaluate preventive measures, and share information with stakeholders.

\subsection{Entrepreneurship}

Based on the key role of entrepreneurship in the economic development of developing countries, the national government has tried to improve entrepreneurship in Iran. This has resulted from the fact that the entrepreneurs have the role of business creation in facing poverty (Brière et al., 2015). Over two recent decades, Iran has accomplished a large number of initiatives to promote the economy. To achieve the aim, the government has focused on the development of small and medium-sized enterprises by fostering entrepreneurship. From 2008 to 2018, the number of the registered entrepreneurs increased from $7 \%$ to $12 \%$ (GEM, 2018). Entrepreneurship is known as a great engine of the country's economy (Rezaei et al., 2017). Different organizations support entrepreneurial development, including the institute of labor and social welfare, the small and medium-sized enterprise development organization, the central bank of Iran, the statistical center of Iran, and science and technology parks. These organizations are supported by the government and different NGOs. However, the country's economy has various problems resulted from the world crises. This imposes an unfavorable business environment, reflected in a negative trade balance, high inflation rate, fluctuation in IRR exchange rate, and insufficient inflow of foreign direct investment (Rezaei et al., 2017).

\section{RESEARCH OBJECTIVE, METHODOLOGY AND DATA}

The aim of the research is to present a new model in order to provide a proper base for clearly analyzing the current situation of firms and identifying the oncoming threats and opportunities. It can lead to substantial growth in the outputs by overcoming the critical challenges through the scheduled actions. For achieving the aim, a new model based on a combination of the neutrosophic set and ANP technique using sustainable development components is proposed to model the entrepreneurial challenges in Iran, a developing country, to reflect different challenges and make a proper decision for dealing with such situations. To achieve the aim, the basic indicators of the sustainable development analysis are divided into three main groups, including economic (EC), environmental (EN), and social (S) components. These main criteria can be fallen into several sub-criteria. Therefore, a list of the main criteria and corresponding 
sub-criteria were extracted from the literature review, and then an interview with the expert team was conducted to modify the list, as depicted in Table 1.

Tab. 1 - Definition of the main and sub-criteria. Source: own research

\begin{tabular}{|c|c|c|c|}
\hline Goal & Criteria & Sub-criteria & Definition \\
\hline \multirow{9}{*}{ 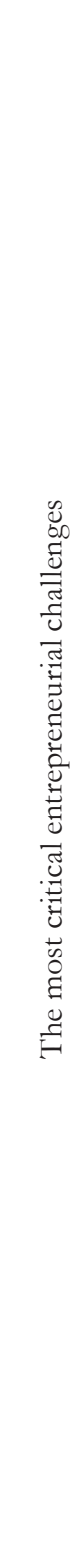 } & \multirow{5}{*}{ 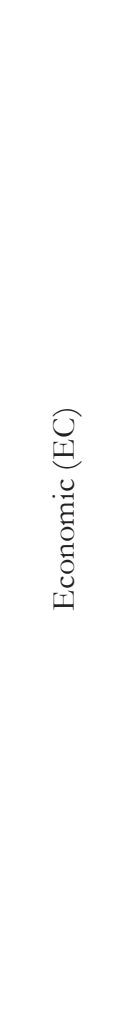 } & $\begin{array}{l}\text { Marketing and selling } \\
\text { (EC1) (Smith, 2005; } \\
\text { Gelard \& Saleh, 2011; } \\
\text { Cantele \& Vernizzi, } \\
\text { 2015) }\end{array}$ & $\begin{array}{l}\text { The aim of a firm is to sell a product or } \\
\text { service and earn a corresponding income. } \\
\text { Therefore, a firm makes income only when } \\
\text { selling a product or service. This factor } \\
\text { reflects how an entrepreneurial firm is capable } \\
\text { of maximizing the rate of returns. }\end{array}$ \\
\hline & & $\begin{array}{l}\text { Financing (EC2) (Smith, } \\
\text { 2005; Dixit et al., 2010; } \\
\text { Gelard \& Saleh, 2011; } \\
\text { Stefanovic et al., 2013; } \\
\text { Lajqi \& Krasniqi, 2017) }\end{array}$ & $\begin{array}{l}\text { It is not easy and simple to funding a new } \\
\text { business because the financial resources are } \\
\text { limited. Based on the reports, more than } \\
70 \% \text { of the firms have experienced financial } \\
\text { problems in the start-up. }\end{array}$ \\
\hline & & $\begin{array}{l}\text { Inflation rate (EC3) } \\
\text { (Smith, 2005; Gelard \& } \\
\text { Saleh, 2011) }\end{array}$ & $\begin{array}{l}\text { It is defined as an overall increase in the } \\
\text { price level during a specific time, normally } \\
\text { expressed as an annual percentage. It plays } \\
\text { an important role in entrepreneurial firms } \\
\text { because this factor is a serious challenge to } \\
\text { many entrepreneurs. }\end{array}$ \\
\hline & & $\begin{array}{l}\text { Sanction (EC4) } \\
\text { (Ramezani, 2018; } \\
\text { Tavakol, 2020; } \\
\text { Jahanshahi \& Brem, } \\
\text { 2020) }\end{array}$ & $\begin{array}{l}\text { It is known as a set of regulations on } \\
\text { punishing countries by imposing some } \\
\text { penalties until such a time as their behavior is } \\
\text { resolved. }\end{array}$ \\
\hline & & $\begin{array}{l}\text { Interest rate (EC5) } \\
\text { (Smith, 2005; Gelard \& } \\
\text { Saleh, 2011) }\end{array}$ & $\begin{array}{l}\text { The proportion of a loaned amount, generally } \\
\text { expressed as an annual percentage, which a } \\
\text { lender charges for the use of assets. }\end{array}$ \\
\hline & \multirow{4}{*}{ 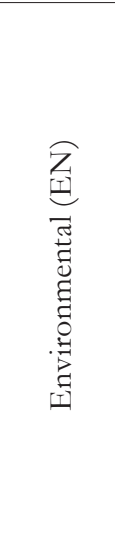 } & $\begin{array}{l}\text { Ecological awareness } \\
\text { (EN1) (Gelard \& Saleh, } \\
\text { 2011) }\end{array}$ & $\begin{array}{l}\text { This factor reflects the impact of our } \\
\text { activities and actions on ecosystems and the } \\
\text { environment. }\end{array}$ \\
\hline & & $\begin{array}{l}\text { Air pollution (EN2) } \\
(\text { Gelard \& Saleh, 2011) }\end{array}$ & $\begin{array}{l}\text { It shows how the air is polluted by the } \\
\text { released harmful material that damages } \\
\text { human health and the planet. }\end{array}$ \\
\hline & & $\begin{array}{l}\text { Water pollution (EN3) } \\
\text { (Gelard \& Saleh, 2011) }\end{array}$ & $\begin{array}{l}\text { This component shows how harmful } \\
\text { substances, including microorganisms or } \\
\text { chemicals, contaminate a water resource; so } \\
\text { that water quality will be degraded. }\end{array}$ \\
\hline & & $\begin{array}{l}\text { Emission of greenhouse } \\
\text { gases (EN4) (Gelard \& } \\
\text { Saleh, 2011) }\end{array}$ & $\begin{array}{l}\text { The gases that trap heat in the atmosphere } \\
\text { and make the planet warmer are known as } \\
\text { greenhouse gases. }\end{array}$ \\
\hline
\end{tabular}




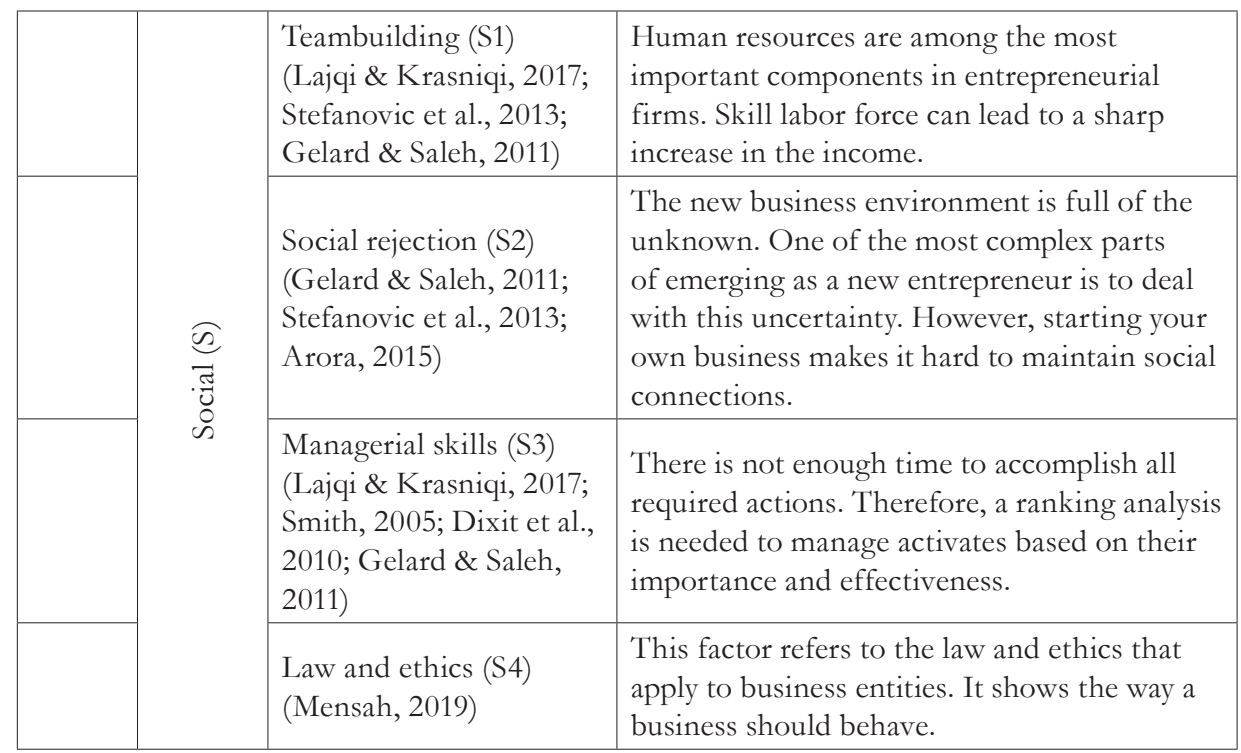

\subsection{Neutrosophic sets}

The fuzzy set, first developed by Zadeh (1965), is a mathematical tool to cope with the uncertainty involved in the decision process. However, there is uncertainty in the data, which is not handled by fuzzy sets (Atanassov, 1986). Therefore, the ordinary fuzzy set has been extended to many new types, including interval-valued fuzzy sets, hesitant fuzzy sets, intuitionistic fuzzy sets, and neutrosophic fuzzy sets. The intuitionistic fuzzy sets, introduced by Atanassov (1986), is a general form of standard fuzzy sets. The intuitionistic fuzzy set takes into account both truthmembership ( $\mathrm{T}$ ) and falsity-membership (F). The truth and falsity memberships belong to closed intervals [0, 1]. An intuitionistic fuzzy set can be defined as (Imanov et al., 2017; Yang et al., 2017; Thao \& Duong, 2019; He \& Wu, 2019; Roszkowska \& Jefmański, 2021):

$0 \leq \mathrm{T}+\mathrm{F} \leq 1$

However, the intuitionistic fuzzy set is disabled to handle the indeterminate and inconsistent information imposed by fuzzy systems. Therefore, neutrosophic sets were developed by Smarandache (2005) to consider all types of information. This approach is a difference of fuzzy and intuitionistic sets based on neutral thought, represented by an indeterminacy membership (I). A neutrosophic set can be defined as the following equation:

$0 \leq \mathrm{T}+\mathrm{I}+\mathrm{F} \leq 3$

This formula shows that a neutrosophic set is dependent on the degree of membership, nonmembership, and indeterminacy. However, there are no constraints between indeterminacy, truth, and falsity values.

Let $\breve{X}$ be a universe of discourse and $\breve{\mathrm{X}}$ be an element in $\breve{\mathrm{X}}$, a neutrosophic set is an object with the following form: 


$$
\breve{A}=\left\{\left\langle\breve{x}: \alpha_{\breve{A}}(\breve{x}), \beta_{\breve{A}}(\breve{x}), \gamma_{\breve{A}}(\breve{x})\right\rangle \mid \breve{x} \in \breve{X}\right\}
$$

where the functions $\alpha, \beta, \gamma: \breve{X} \rightarrow]^{-} 0,1^{+}[$indicate respectively the degree of membership, indeterminacy, and non-membership of the element $\breve{x} \in \breve{X}$ to the set $\breve{A}$. For two neutrosophic sets: $\breve{A}=\left\{\left\langle\breve{x}: \alpha_{\breve{A}}(\breve{x}), \beta_{\breve{A}}(\breve{x}), \gamma_{\breve{A}}(\breve{x})\right\rangle \mid \breve{x} \in \breve{X}\right\}$ and $\breve{B}=\left\{\left\langle\breve{x}: \alpha_{\breve{B}}(\breve{x}), \beta_{\breve{B}}(\breve{x}), \gamma_{\breve{B}}(\breve{x})\right\rangle \mid \breve{x} \in \breve{X}\right\}$

The relations can be described as follows:

$\breve{A}=\breve{B}$ if and only if $\alpha_{\breve{A}}(\breve{x})=\alpha_{\breve{B}}(\breve{x}), \beta_{\breve{A}}(\breve{x})=\beta_{\breve{B}}(\breve{x}), \gamma_{\breve{A}}(\breve{x})=\gamma_{\breve{B}}(\breve{x})$

$\breve{A} \subseteq \breve{B}$ if and only if $\alpha_{\breve{A}}(\breve{x}) \leq \alpha_{\breve{B}}(\breve{x}), \beta_{\breve{A}}(\breve{x}) \geq \beta_{\breve{B}}(\breve{x}), \gamma_{\breve{A}}(\breve{x}) \geq \gamma_{\breve{B}}(\breve{x})$

$\breve{A} \cap \breve{B}=\left\{\left\langle\breve{x}:\left(\alpha_{\breve{A}} \wedge \alpha_{\breve{B}}\right)(\breve{x}),\left(\beta_{\breve{A}} \vee \beta_{\breve{B}}\right)(\breve{x}),\left(\gamma_{\breve{A}} \vee \gamma_{\breve{B}}\right)(\breve{x})\right\rangle \mid \breve{x} \in \breve{X}\right\}$

$\breve{A} \cup \breve{B}=\left\{\left\langle\breve{x}:\left(\alpha_{\breve{A}} \vee \alpha_{\breve{B}}\right)(\breve{x}),\left(\beta_{\breve{A}} \wedge \beta_{\breve{B}}\right)(\breve{x}),\left(\gamma_{\breve{A}} \wedge \gamma_{\breve{B}}\right)(\breve{x})\right\rangle \mid \breve{x} \in \breve{X}\right\}$

$\breve{A}^{-1}=\left\{\left\langle\breve{x}: \gamma_{\breve{A}}(\breve{x}), 1-\beta_{\breve{A}}(\breve{x}), \alpha_{\breve{A}}(\breve{x})\right\rangle \mid \breve{x} \in \breve{X}\right\}$

$0_{\tilde{n}}=(0,1,1)$ and $1_{\breve{n}}=(1,0,0)$

where $\vee$ indicates the $\mathrm{t}$-conorm and $\wedge$ denotes the $\mathrm{t}$-norm.

Let $\tilde{t}_{i j}=\left\langle\left(t_{1}, y_{1}, z_{1}\right), \alpha_{\tilde{i}}, \theta_{\tilde{i}}, \beta_{\tilde{t}}\right\rangle$ be a single triangular neutrosophic number; then the score degree is calculated as (Sarucan et al., 2021):

$$
C\left(\tilde{t}_{i j}\right)=\frac{1}{8}\left[t_{1}+y_{1}+z_{1}\right] \times\left(2+\alpha_{i}-\theta_{i}-\beta_{i}\right)
$$

\subsection{The proposed model}

The analytic network process (ANP) technique is developed to solve the problem of mutual dependency between the elements; whereas, conventional methods are only capable of solving the problem of independence among the elements. The ANP uses a decomposing process to convert a complex decision problem into several simple issues. This technique employs a pairwise comparison approach to obtain the weight of the parameters. The ANP method can consider both interaction and feedback within clusters of elements (inner dependence) and between clusters (external reliance).

However, the ANP technique uses human judgment to obtain the relative importance of elements. Therefore, the inherent uncertainty associated with the judicial process, which has a significant impact on the results, cannot be considered in the modeling procedure. To overcome such situations, the combination of the ANP method and neutrosophic sets can take into account the uncertainty and complexity imposed by the decision process. This paper proposes a robust model based on the ANP method and neutrosophic sets (NANP) to handle interdependency relationships between elements to obtain a reliable result. The proposed model can be described as follows:

Step 1: Definition of the problem and determining the decision elements. The model structure comprises four levels. The goal is located in the first level; the criteria (sustainable development components) and their corresponding sub-criteria are situated in the second and last levels, respectively.

Step 2: Definition of the neutrosophic numbers used to make a comparison between the evaluation criteria by using a two-by-two pairwise comparison. 
Step 3: The comparison of the criteria and sub-criteria is made by the assumption that there is no dependence among the sustainable development components.

Step 4: The analysis of the impact of each factor on every other factor is accomplished to obtain the inner dependence among the criteria and sub-criteria. The dependences among the elements are extracted as schematically shown in Fig. 1.

Step 5: Calculation of the relative weight by multiplying the local weights with inner dependency weights.

Step 6: The overall weights of the factors are computed by multiplying the final weights of the factors with the local weights of the sub-factors. The proposed model creates a real insight for both managers and decision-makers for a better understanding of the firm's challenges.

\section{RESULTS AND DISCUSSION}

The framework proposed in this paper applies a combined model based on ANP, neutrosophic sets, and sustainable development indicators to provide a systematic and organized approach for prioritizing the most critical entrepreneurial challenges in Iran. To achieve the aim, sustainable development indicators are firstly identified by literature review and interviews with the decision team; then the interdependency relationships are extracted by face-to-face interviews with the decision team; finally, the most critical challenges are prioritized in descending order by the NANP technique. This research identifies thirteen challenges, based on experts' opinions and literature review, to provide a holistic perspective to the challenges faced by the entrepreneurial firms in a new environment.

As seen in Table 1 and Figure 1, thirteen parameters are classified by using sustainable development components. These challenging criteria should be prioritized in descending order because of financial and time limitations in order to make a proper decision. The model is fulfilled as described in the following:

Step 1: Construct the hierarchical model. The first step converts a complex problem into a simple one using a hierarchical structure (as seen in Figure 1). The first level contains the overall goal, the second level comprises the main criteria, and the last level indicates the sub-criteria.

Step 2: Define the neutrosophic numbers. In this step, the neutrosophic numbers based on the 1-9 Saaty scale (Saaty, 1996) are defined. Linguistic terms and corresponding neutrosophic triangular scales are derived from Sarucan et al. (2021).

Step 3: Make the pairwise comparison. The pairwise comparisons are made by assuming that there is no dependence between the two components (Table 2).

After constructing the decision matrix, the values are transferred into crisp ones. Then, for creating the normalized matrix, the sum of each column is computed to divide each matrix element into it. Finally, the average of the row elements of the normalized matrix is calculated. The results are shown in Table 3. From the table, it is clear that the last column lists the local weight of the criteria. Based on the basic concepts of the pairwise comparison matrix, for achieving a reasonable solution, it is required to check whether the preference relation is consistent or not before deriving the 
priorities of the elements. Consistency plays a significant role in preference relations and the lack of consistency of preference relations may lead to misleading solutions (Xu \& Liao, 2014). The consistency ratio (CR) (Lashgari et al., 2012; Zamani et al., 2014) is available in the last row of the table. The CR value is less than 0.1 . Therefore, it is acceptable. Similar computations are accomplished to obtain the weights of sub-criteria. Table 4 depicts the comparison matrix of subcriteria. The local weights of the criterion are listed in the last column of the table.

Step 4: Obtain the inner dependence between the criteria and sub-criteria. In this step, based on the relationships depicted in Fig. 1, the impact of each factor on every other factor is calculated to obtain the inner dependence. The following table (Table 5) depicts the inner dependency relationships. The last column of the table lists the local weights of parameters.

Step 5: Calculation of the relative weight by multiplying the local weights resulted from step 3 with the inner dependency weights resulted from step 4.

After calculating the inner dependency weights, the interdependent weights can be obtained by multiplying the inner dependency weights with the local weights extracted from step 3. Therefore, the interdependent weights of the sustainable development factors are calculated as follows:

$w_{\text {main-factors }}=\left(\begin{array}{ccc}1 & 0.79 & 0.64 \\ 0.27 & 1 & 0.36 \\ 0.73 & 0.21 & 1\end{array}\right) \times\left[\begin{array}{l}0.54 \\ 0.23 \\ 0.23\end{array}\right]=\left[\begin{array}{l}0.43 \\ 0.23 \\ 0.34\end{array}\right]$

From the above matrix, it can be shown that the weights are changed from $0.54,0.23$, and 0.23 into $0.43,0.23$, and 0.34 , respectively. Likewise, the interdependent weights of the subfactors can be obtained. From the outputs, it can be resulted that the local weights for economic factors changed from $0.33,0.25,0.2,0.11$, and 0.11 to $0.25,0.21,0.15,0.29$, and 0.10 , respectively. Likewise, the local weights for environmental factors are varied from $0.16,0.22,0.25$, and 0.38 to $0.14,0.22,0.27$, and 0.37 , respectively. Finally, the local weights for social factors changed from $0.1,0.32,0.16$, and 0.42 to $0.09,0.29,0.21$, and 0.41 , respectively. This demonstrates the inner dependency relationships can lead to a significant change in the local weights. From the economic point of view, these weights show which challenge is more important for the purpose of resource allocation.

Step 6: The overall weights are obtained by multiplying the independent weights of the factors with those of the sub-factors. Table 6 lists the local and overall weights of the factors and subfactors. According to the last table, the law and ethics parameter (S4) is located in the highest rank (most important parameter). Sanction factor (EC4) and marketing and selling factor (EC1) are situated in the second and third rank, respectively. In addition, the teambuilding parameter (S1) with the lowest rank is the least important parameter.

Tab. 2 - The neutrosophic comparison matrix of main-criteria. Source: own research

\begin{tabular}{|l|l|l|l|}
\hline & EC & EN & S \\
\hline EC & $\widetilde{1}$ & 3 & 3 \\
\hline EN & $\widetilde{3}^{-1}$ & $\widetilde{1}$ & $\tilde{1}$ \\
\hline S & $\widetilde{3}^{-1}$ & $\tilde{1}$ & $\widetilde{1}$ \\
\hline
\end{tabular}


Tab. 3 - The comparison matrix of main-criteria. Source: own research

\begin{tabular}{|l|l|l|l|l|}
\hline & EC & EN & S & $W_{\text {criterion }}$ \\
\hline EC & $0.71 * *$ & 0.46 & 0.46 & 0.54 \\
\hline EN & 0.15 & 0.27 & 0.27 & 0.23 \\
\hline S & 0.15 & 0.27 & 0.27 & 0.23 \\
\hline$C^{*}=0.05$
\end{tabular}

* Consistency ratio; ** The normalized value

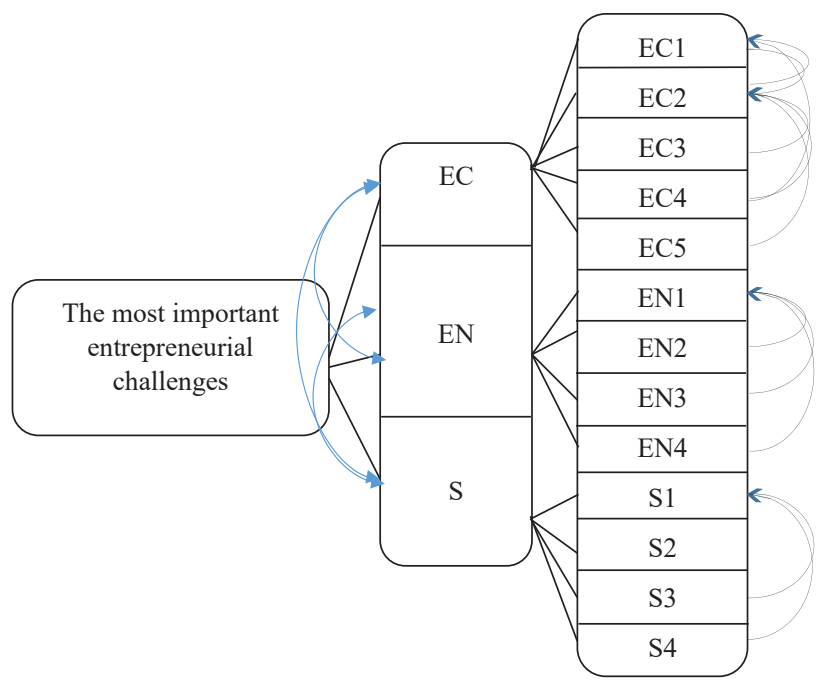

Fig. 1 - The structure of the problem (the links reflect there is a dependency or direct and interdependency or indirect relationships between two elements). Source: own research

Tab. 4 - The comparison matrix of the sub-criteria. Source: own research

\begin{tabular}{|c|c|c|c|c|c|c|c|c|c|c|c|c|c|c|c|}
\hline & & EC1 & $\mathrm{EC} 2$ & EC3 & $\mathrm{EC} 4$ & EC5 & EN1 & EN2 & EN3 & EN4 & S1 & S2 & S3 & S4 & Wcriterion \\
\hline \multirow[t]{5}{*}{ EC } & EC1 & 0.43 & 0.42 & 0.32 & 0.25 & 0.25 & & & & & & & & & 0.33 \\
\hline & EC2 & 0.2 & 0.27 & 0.32 & 0.22 & 0.25 & & & & & & & & & 0.25 \\
\hline & EC3 & 0.2 & 0.13 & 0.21 & 0.25 & 0.22 & & & & & & & & & 0.20 \\
\hline & EC4 & 0.09 & 0.13 & 0.04 & 0.14 & 0.14 & & & & & & & & & 0.11 \\
\hline & EC5 & 0.09 & 0.06 & 0.1 & 0.14 & 0.14 & & & & & & & & & 0.11 \\
\hline \multirow[t]{4}{*}{ EN } & EN1 & & & & & & 0.19 & 0.22 & 0.12 & 0.1 & & & & & 0.16 \\
\hline & EN2 & & & & & & 0.19 & 0.22 & 0.25 & 0.22 & & & & & 0.22 \\
\hline & EN3 & & & & & & 0.29 & 0.22 & 0.25 & 0.22 & & & & & 0.25 \\
\hline & EN4 & & & & & & 0.32 & 0.34 & 0.38 & 0.47 & & & & & 0.38 \\
\hline \multirow[t]{4}{*}{ S } & S1 & & & & & & & & & & 0.11 & 0.08 & 0.1 & 0.13 & 0.10 \\
\hline & S2 & & & & & & & & & & 0.19 & 0.37 & 0.33 & 0.4 & 0.32 \\
\hline & S3 & & & & & & & & & & 0.17 & 0.18 & 0.21 & 0.08 & 0.16 \\
\hline & S4 & & & & & & & & & & 0.54 & 0.37 & 0.36 & 0.4 & 0.42 \\
\hline CR & & \multicolumn{5}{|l|}{0.08} & \multicolumn{4}{|l|}{0.08} & \multicolumn{4}{|l|}{0.07} & \\
\hline
\end{tabular}


Tab. 5 - The inner-dependency matrices. Source: own research

\begin{tabular}{|c|c|c|c|c|c|c|c|c|c|c|c|c|c|c|c|c|c|}
\hline$\overline{\mathrm{EC}}$ & EN & $\mathrm{S}$ & $\mathrm{W}^{*}$ & EN & $\mathrm{EC}$ & $\mathrm{S}$ & \multicolumn{2}{|c|}{$\mathrm{W}$} & $\mathrm{S}$ & EC & EN & \multicolumn{2}{|c|}{$\mathrm{W}$} & S1 & S3 & S4 & $\mathrm{W}$ \\
\hline EN & $\tilde{1}$ & $\tilde{3}$ & 0.27 & $\mathrm{EC}$ & $\tilde{1}$ & $\tilde{4}$ & \multicolumn{2}{|c|}{0.79} & $\mathrm{EC}$ & $\tilde{1}$ & $\tilde{2}$ & \multicolumn{2}{|c|}{0.64} & S3 & $\tilde{1}$ & $\tilde{3}$ & 0.73 \\
\hline $\mathrm{S}$ & $\tilde{3}^{-1}$ & $\tilde{1}$ & 0.73 & $\mathrm{~S}$ & $\tilde{4}^{-1}$ & $\tilde{1}$ & \multicolumn{2}{|c|}{0.21} & EN & $\tilde{2}^{-1}$ & $\tilde{1}$ & \multicolumn{2}{|c|}{0.36} & S4 & $\tilde{3}^{-1}$ & $\tilde{1}$ & 0.27 \\
\hline $\mathrm{EC} 1$ & $\mathrm{EC} 2$ & EC4 & W & $\mathrm{EC} 2$ & $\mathrm{EC} 1$ & $\mathrm{EC} 3$ & EC4 & EC5 & \multicolumn{2}{|c|}{ W } & EN1 & EN2 & EN3 & EN4 & \multicolumn{3}{|c|}{ W } \\
\hline EC2 & $\tilde{1}$ & $\tilde{3}^{-1}$ & 0.27 & EC1 & $\tilde{1}$ & $\tilde{2}$ & $\tilde{2}^{-1}$ & $\tilde{1}$ & \multicolumn{2}{|c|}{0.25} & EN2 & $\tilde{1}$ & $\tilde{2}^{-1}$ & $\tilde{1}$ & \multicolumn{3}{|c|}{0.27} \\
\hline EC4 & $\tilde{3}$ & $\tilde{1}$ & 0.73 & EC3 & $\tilde{2}^{-1}$ & $\tilde{1}$ & $\tilde{3}^{-1}$ & $\tilde{1}$ & \multicolumn{2}{|c|}{0.16} & EN3 & $\tilde{2}$ & $\tilde{1}$ & $\tilde{1}$ & \multicolumn{3}{|c|}{0.39} \\
\hline & & & & EC4 & $\tilde{2}$ & $\tilde{3}$ & $\tilde{1}$ & $\tilde{3}$ & \multicolumn{2}{|c|}{0.4} & EN4 & $\tilde{1}$ & $\tilde{1}$ & $\tilde{1}$ & \multicolumn{3}{|c|}{0.34} \\
\hline & & & & EC5 & $\tilde{1}$ & $\tilde{1}$ & $\tilde{3}^{-1}$ & $\tilde{1}$ & \multicolumn{2}{|c|}{0.19} & & & & & & & \\
\hline \multicolumn{4}{|c|}{$\mathrm{CR}=0.0$} & \multicolumn{7}{|c|}{$\mathrm{CR}=0.079$} & \multicolumn{7}{|c|}{$\mathrm{CR}=0.097$} \\
\hline
\end{tabular}

*Weight

Tab. 6 - The overall weights of factors. Source: own research

\begin{tabular}{|l|l|l|l|l|l|l|l|l|l|l|l|l|l|}
\hline Factors & EC1 & EC2 & EC3 & EC4 & EC5 & EN1 & EN2 & EN3 & EN4 & S1 & S2 & S3 & S4 \\
\hline Weights & 0.108 & 0.093 & 0.066 & 0.124 & 0.043 & 0.031 & 0.052 & 0.061 & 0.085 & 0.031 & 0.098 & 0.071 & 0.137 \\
\hline Ranking & 3 & 5 & 8 & 2 & 11 & 12 & 10 & 9 & 6 & 13 & 4 & 7 & 1 \\
\hline
\end{tabular}

A key aspect of business management is to identify the challenges and threats in a sophisticated social, economic, and environmental situation. This process helps decision-makers manage financial and time resources by allocating them in a systematic and logical manner. However, the proposed model provides an analytical base to manage the limitation of the resources under an evaluation process. The model uses a mathematical tool to formulate the problem under consideration. This model can consider all quantitative and qualitative components under a vagueness of the environment. The results demonstrate that there is an overall rank in descending order. This means some challenges are more important than others.

Based on the results derived from Table 6, the following conclusions can be reached: the effect of the law and ethics (S4) challenge is more important than that of the other challenges. Therefore, this challenge should be firstly taken into account to reduce the resulted risks. The effect of the teambuilding parameter (S1) is less important than that of the other challenges. Therefore, this challenge can be later considered in the process of improvement.

The results extracted from the proposed model show that law and ethics challenges, with the weight value of 0.137 , play the most significant role in new businesses. Sanction and marketing, and selling challenges with the weight value of 0.124 and 0.108 are located in the second and third important, respectively. On the other hand, teambuilding and ecological awareness challenges with the weight value of 0.031 and 0.031 , respectively, are located in the last ranks. The results demonstrate that decision-makers should manage the key challenges to timely improve the business environment. Therefore, all stakeholders should work together to cope with the most critical challenges. This can lead to new businesses become more competitive in national and international markets. The government should make an attempt to improve the law and ethics situations; so that it provides a condition that encourages foreign and domestic investors to expand their business in Iran. This paper provides significant suggestions for decision-makers and authorities. Authorities may acknowledge how sustainability indicators can influence future strategies; so that they can monitor the procedures to simultaneously attain economic, social, and environmental aims. Based on the model, a decision-maker can obtain a clearer perception 
of the current situation and find a solution to fill the gaps. This leads to the best performance by performing sustainability activities be achieved. However, this research provides a deeper understanding of the current situation. By making more suitable principles, it can help decisionmakers follow sustainability development.

This research is in line with previous studies that have examined the entrepreneurial challenges in Iran (Rezaei et al., 2017; Ramezani, 2018). Ramezani (2018) suggested that the government should play a vital role in facing law and ethics challenges. The government should provide a reliable base for making a competitive advantage. The results of the research are partially compatible with the analyses issued by other international researchers. Brière et al. (2015) demonstrated that financial and regulations are among the most critical challenges in South Africa. Stefanovic et al. (2013) showed lack of financial resources, administrative obstacles, insufficiently qualified labor, lack of information on markets and technologies, and non-compliance with standards are known as the major challenges in Serbia.

However, by using a small amount of information, this paper proposes a comprehensive model to conduct a comparative assessment of sustainable challenges, identify the most critical factors that significantly impact the sustainable development, calculate the extent of the environmental, social, and economic sustainability, find the gaps between the current and ideal situations, allocate the financial and non-financial resources, prevent the resources from wasting, evaluate the oncoming scenarios for future actions, and assess the efficiency of the authorities.

\section{CONCLUSION}

Although an entrepreneurial firm encounters challenges, a new entrepreneur faces a set of challenges to overcome. However, based on the limitations of resources and time, it is necessary to prioritize the most critical entrepreneurial challenges. In this study, an integrated model based on the ANP method and sustainable development indicators under neutrosophic sets is proposed. The ANP technique is known as the preferred technique for extracting the importance weights when there is interdependence between elements. The model uses a systematic approach to obtain the most and least important entrepreneurial challenges in Iran. This model can reflect competitiveness by designing and selling goods at prices, quality, and other attractive features offered by the competitors. This model helps authorities make better decisions in coping with such sophisticated problems. The proposed model is capable of considering both the uncertainty and inner-dependency relationships. The results demonstrate that S4 (law and ethics) is the most critical factor with a value of 0.137 . In addition, S1 (teambuilding) is located in the lowest rank with 0.031. Therefore, authorities are advised to improve law and ethics. Finally, it is recommended that decision-makers use the proposed model to analyze their challenges for development or planning purposes. Since the proposed model is sensitive to the problem description and its components, researchers should appropriately define a problem and corresponding dependency and interdependency relationships. Researchers should take into account the mentioned concerns to prevent the results from being unreliable. However, it should be noted that a wrong design of the problem can influence the interpretation of the findings. One other limitation of this study is the focus on a developing country. In future studies, the research can be limited to a 
developed country to precisely compare the findings. The other significant future contribution is to compare the findings of the proposed model with those of other techniques to identify the significant factors in a more reliable and accurate way.

\section{References}

1. Abdel-Basset, M., Ali, M., \& Atef, A. (2020). Uncertainty assessments of linear time-cost tradeoffs using neutrosophic set. Computers \& Industrial Engineering, 141, 106286. https://doi. org/10.1016/j.cie.2020.106286

2. Arora, R. (2015). Perspectives of Entrepreneurship and Its Impact on Stakeholders' CoCreation. Entrepreneurship and Stakeholder Co-Creation, Entrepreneurial Challenges in the 21st Century, Creating Stakeholder Value Co-Creation (Edited by Kaufmann and Shams), chapter 1, 1-11.

3. Atanassov, K. T. (1986). Intuitionistic fuzzy sets. Fuzzy Sets and Systems, 20 (1), 87-96. https:// doi.org/10.1016/S0165-0114(86)80034-3

4. Azimi, R., Yazdani-Chamzini, A., Fouladgar, M. M., Zavadskas, E. K., \& Basiri, M. H. (2011). Ranking the strategies of the mining sector through ANP and TOPSIS in a SWOT framework. Journal of Business Economics and Management, 12 (4), 670-689. https://doi.org/10.384 6/16111699.2011.626552

5. Bahl, M., Lahiri, S., \& Mukherjee, D. (2021). Managing internationalization and innovation tradeoffs in entrepreneurial firms: Evidence from transition economies. Journal of World Business, 56 (1), 101-150. https://doi.org/10.1016/j.jwb.2020.101150

6. Bai, W., Liu, R., \& Zhou, L. (2020). Enhancing the learning advantages of newness: The role of internal social capital in the international performance of young entrepreneurial firms. Journal of International Management, 26 (2), 100733. https://doi.org/10.1016/j.intman.2020.100733

7. Baušys, R., \& Juodagalviene, B. (2017). Garage location selection for the residential house by WASPAS-SVNS method. Journal of Civil Engineering and Management, 23 (3), 421-429. https:// doi.org/10.3846/13923730.2016.1268645

8. Biswas, P., Pramanik, S., \& Giri, B. C. (2016). TOPSIS method for multi-attribute group decision making under a single-valued neutrosophic environment. Neural Computing and Applications, 27 (3), 727-737. https://doi.org/10.1007/s00521-015-1891-2

9. Brière, S., Tremblay, M., \& Daou, A. (2015). Challenges facing international projects for entrepreneurial development in South Africa. Development Southern Africa, 32 (6), 711-725. https://doi.org/10.1080/0376835X.2015.1063981

10. Broumi, S., Deli, I., \& Smarandache, F. (2014). Neutrosophic parametrized soft set theory and its decision-making. International Frontier Science Letters, 1, 1-10. https://doi.org/10.18052/www. scipress.com/IFSL.1.1

11. Cantele, S., \& Vernizzi, S. (2015). Value Co-Creation and Entrepreneurial Challenges in Business Networks: What Factors Impact Upon the Performance of Firms in Networks? Co-Creation and Network Firms' Performance, Entrepreneurial Challenges in the 21st Century, Creating Stakeholder Value Co-Creation (Edited by Kaufmann, H. R., Shams, S.M. R.), 4, 47-68. 
12. Dixit, M. R., Sharma, S., \& Karna, A. (2010). New environmental stimuli, challenges of entrepreneurial firms and growth leaps: evidence from multisector case studies. International Journal of Entrepreneurial Venturing, 1 (3), 264-290. https://doi.org/10.1504/IJEV.2010.030977

13. Fouladgar, M. M., Yazdani-Chamzini, A., Lashgari, A., Zavadskas, E. K., \& Turskis, Z. (2012). Maintenance Strategy Selection using AHP and COPRAS under fuzzy environment. International Journal of Strategic Property Management, 16 (1), 85-104. https://doi.org/10.3846/1648 715X.2012.666657

14. Garg, H., \& Nancy, L. (2017). Non-linear programming method for multi-criteria decisionmaking problems under interval neutrosophic set environment. Applied Intelligence, 48, 2199-2213. https://doi.org/10.1007/s10489-017-1070-5

15. Gelard, P., \& Saleh, K. E. (2011). A Model for Select Best Entrepreneurs in Iran. Australian Journal of Basic and Applied Sciences, 5 (6), 1180-1192.

16. GEM. (2018). Global entrepreneurship monitor. Iran: GEM Iran Report.

17. Ginevicius, R. (2019). Quantitative Assessment of the Compatibility of the Development of Socioeconomic Systems. Journal of Competitiveness, 11 (2), 36-50. https://doi.org/10.7441/ joc. 2019.02 .03

18. He, X., \& Wu, Y. (2019). Global Research Trends of Intuitionistic Fuzzy Set: A Bibliometric Analysis. Journal of Intelligent Systems, 28 (4), 621-631. https://doi.org/10.1515/jisys-2017-0240

19. Hu, J., Pan, L., \& Chen, X. (2017). An interval neutrosophic projection-based VIKOR method for selecting doctors. Cognitive Computing, 9 (6), 801-816. https://doi.org/10.1007/s12559-0179499-8

20. Imanov, G., Garibli, E., \& Akbarov, R. (2017). Analysis of socioeconomic development by intuitionistic linguistic fuzzy numbers. Procedia Computer Science, 120, 341-348. https://doi. org/10.1016/j.procs.2017.11.248

21. Jahanshahi, A. A., \& Brem, A. (2020). Entrepreneurs in post-sanctions Iran: Innovation or imitation under conditions of perceived environmental uncertainty? Asia Pacific Journal of Management, 37, 531-551. https://doi.org/10.1007/s10490-018-9618-4

22. Jiang, W., \& Shou, Y. (2017). A novel single-valued neutrosophic set similarity measure and its application in multicriteria decision-making. Symmetry, 9 (8), 127. https://doi.org/10.3390/ $\operatorname{sym} 9080127$

23. Jiang, W., Chai, H., Shao, J., \& Feng, T. (2018). Green entrepreneurial orientation for enhancing firm performance: A dynamic capability perspective. Journal of Cleaner Production, 198, 1311-1323. https://doi.org/10.1016/j.jclepro.2018.07.104

24. Khatter, K. (2021). Interval-valued trapezoidal neutrosophic set: multi-attribute decision making for prioritization of non-functional requirements. Journal of Ambient Intelligence and Humanized Computing, 12, 1039-1055. https://doi.org/10.1007/s12652-020-02130-8

25. Lajqi, S., \& Krasniqi, B. A. (2017). Entrepreneurial growth aspirations in challenging environment: The role of institutional quality, human and social capital. Strategic Change, 26 (4), 385-401. https://doi.org/10.1002/jsc.2139 
26. Lashgari, A., Yazdani-Chamzini, A., Fouladgar, M. M., Zavadskas, E. K., Shafiee, S. H., \& Abbate, N. (2012). Equipment Selection Using Fuzzy Multi-Criteria Decision Making Model: Key Study of Gole Gohar Iron Min. Inæinerine Ekonomika-Engineering Economics, 23 (2), 125-136. https://doi.org/10.5755/j01.ee.23.2.1544

27. Laurett, R., Paço, A., \& Mainardes, E. W. (2021). Sustainable Development in Agriculture and its Antecedents, Barriers and Consequences - An Exploratory Study. Sustainable Production and Consumption, 27, 298-311. https://doi.org/10.1016/j.spc.2020.10.032

28. Li, C., Xu, Y., Gill, A., Haider, Z. A., \& Wang, Y. (2019). Religious beliefs, socially responsible investment, and cost of debt: Evidence from entrepreneurial firms in India. Emerging Markets Review, 38, 102-114. https://doi.org/10.1016/j.ememar.2018.12.001

29. Li, Y., Wang, J., \& Wang, T. (2019). A Linguistic Neutrosophic Multi-criteria Group DecisionMaking Approach with EDAS Method. Arabian Journal for Science and Engineering, 44, $2737-$ 2749. https://doi.org/10.1007/s13369-018-3487-5

30. Liang, R., Wang, J., \& Zhang, H. (2017). Evaluation of e-commerce websites: an integrated approach under a single-valued trapezoidal neutrosophic environment. Knowledge-Based Systems, 135, 44-59. https://doi.org/10.1016/j.knosys.2017.08.002

31. Mashokhida, A., Khabibovich, A.A., Pálka, P., \& Shakhlo, R. (2018). The competitiveness and sustainable economic development of Tajikistan regions. Journal of Competitiveness, 10 (1), 73-88. https://doi.org/10.7441/joc.2018.01.05

32. Matricano, D. (2020). Entrepreneurship trajectories: entrepreneurial opportunities, business models, and firm performanc. Academic Press.

33. Mensah, J. (2019). Sustainable development: Meaning, history, principles, pillars, and implications for human action: Literature review. Cogent Social Sciences, 5 (1), 1653531. https:// doi.org/10.1080/23311886.2019.1653531

34. Neumann, T. (2020). The impact of entrepreneurship on economic, social and environmental welfare and its determinants: a systematic review. Management Review Quarterly, 71, 553-584. https://doi.org/10.1007/s11301-020-00193-7

35. Nguyen, T. T. D. (2020). An Empirical Study on the Impact of Sustainability Reporting on Firm Value. Journal of Competitiveness, 12 (3), 119-135. https://doi.org/10.7441/joc.2020.03.07

36. Nousheen, A., Zai, S. A. Y., Waseem, M., \& AliKhan, S. H. (2020). Education for sustainable development (ESD): Effects of sustainability education on pre-service teachers' attitude towards sustainable development (SD). Journal of Cleaner Production, 250, 119537. https://doi. org/10.1016/j.jclepro.2019.119537

37. Peng, H. G., Zhang, H. Y., \& Wang, J. Q. (2016). Probability multi-valued neutrosophic sets and their application in multi-criteria group decision-making problems. Neural Computing and Applications, 30, 563-583. https://doi.org/10.1007/s00521-016-2702-0

38. Peng, X., \& Smarandache, F. (2020). New multiparametric similarity measure for neutrosophic set with big data industry evaluation. Artificial Intelligence Review, 53, 3089-3125. https://doi. org/10.1007/s10462-019-09756-x 
39. Rae, D. (2017). Developing entrepreneurial leadership: the challenge for sustainable organisations. International Journal of Work Innovation, 2 (1), 76-100. https://doi.org/10.1504/ IJWI.2017.080725

40. Ragozzino, R., \& Reuer, J. J. (2010). The opportunities and challenges of entrepreneurial acquisitions. European Management Review, 7 (2), 80-90. https://doi.org/10.1057/emr.2010.5

41. Rajagopal, A. (2021). The Entrepreneurial Challenges Ahead. In: Epistemological Attributions to Entrepreneurial Firms. Cham: Palgrave Macmillan.

42. Ramezani, A. (2018). How US sanctions will impact Iranian startups. Retrieved from: https:// www.al-monitor.com/originals/2018/05/iran-jcpoa-nuclear-sanctions-reimposition-startupimpact.html

43. Rezaei, S., Dana, L. P., \& Ramadani, V. (2017). Introduction to Iranian Entrepreneurship. Iranian Entrepreneurship Deciphering the Entrepreneurial Ecosystem in Iran and in the Iranian Diaspora. New York: Springer International Publishing AG.

44. Rogers, P. P., Jalal, K. F., \& Boyd, J. A. (2008). An introduction to sustainable development. New York: Glen Educational Foundation, Inc.

45. Roszkowska, E., \& Jefmański, B. (2021). Interval-Valued Intuitionistic Fuzzy Synthetic Measure (I-VIFSM) Based on Hellwig's Approach in the Analysis of Survey Data. Mathematics, 9 (3), 201. https://doi.org/10.3390/math9030201

46. Saaty, T. L. (1996). Decision Making with Dependence and Feedback: The Analytic Network Process. Pittsburgh: RWS Publications.

47. Sarucan, A., Baysal, M. E., \& Engin, O. (2021). Physician Selection with a Neutrosophic Multi-criteria Decision Making Method. C. Kahraman et al. (Eds.): INFUS 2020, AISC 1197. Cham: Springer Nature Switzerland AG.

48. Shafieisabet, N., \& Haratifard, S. (2020). The empowerment of local tourism stakeholders and their perceived environmental effects for participation in sustainable development of tourism. Journal of Hospitality and Tourism Management, 45, 486-498. https://doi.org/10.1016/j. jhtm.2020.10.007

49. Shulla, K., Filho, W. L., Sommer, J. H., Salvia, A. L., \& Borgemeister, C. (2020). Channels of collaboration for citizen science and the sustainable development goals. Journal of Cleaner Production, 264, 121735. https://doi.org/10.1016/j.jclepro.2020.121735

50. Smarandache, F. (2005). Neutrosophic set-a generalization of the intuitionistic fuzzy set. International Journal of Pure and Applied Mathematics, 24 (3), 287-297.

51. Smith, W. L. (2005). Choosing an entrepreneurial development system: the concept and the challenges'. International Journal of Management and Enterprise Development, 2 (3), 349-359.

52. Stefanovic, S., Ivanovic-Djukić, M., \& Jankovic-Milic, V. (2013). The Analysis of Key Challenges and Constraints to the Stability and Growth of an Entrepreneurial Sector in Serbia. Journal of Balkean and Near Eastern Studies, 15 (3), 346-365. https://doi.org/10.1080/1944 8953.2013.789330

53. Tavakol, M. (2020). Sanctions and domestic constraints cripple Iran's startups. Retrieved from: https://www.atlanticcouncil.org/blogs/iransource/sanctions-and-domestic-constraintscripple-irans-startups/ 
54. Taylor, K. (2021). An analysis of the entrepreneurial institutional ecosystems supporting the development of hybrid organizations: The development of cooperatives in the U.S. Journal of Environmental Management, 286, 112244. https://doi.org/10.1016/j.jenvman.2021.112244

55. Thao, N. X., \& Duong, T. T. T. (2019). Selecting target market by similar measures in interval intuitionistic fuzzy set. Technological and Economic Development of Economy, 25 (5), 934-950. https://doi.org/10.3846/tede.2019.10290

56. Thong, N.T, Lan, L. T. H., Chou, S. Y., Son, L. H., Dong, D. D., \& Ngan, T. T. (2020). An Extended TOPSIS Method with Unknown Weight Information in Dynamic Neutrosophic Environment. Mathematics, 8 (3), 401. https://doi.org/10.3390/math8030401

57. Wang, N., \& Zhang, H. (2017). Probability multivalued linguistic neutrosophic sets for multicriteria group decision-making. International Journal of Uncertainty Quantification, 7 (3), 207-228. https://doi.org/10.1615/Int.J.UncertaintyQuantification.2017019632

58. Wang, Z., \& Liu, L., (2016). Optimized PROMETHEE based on interval neutrosophic sets for new energy storage alternative selection. Revista Tecnica de la Facultad de Ingenieria Universidad del Zulia, 39 (9), 69-77.

59. Welter, F., \& Smallbone, D. (2011). Institutional Perspectives on Entrepreneurial Behavior in Challenging Environments. Journal of Small Business Management, 49 (1), 107-125. https://doi. org/10.1111/j.1540-627X.2010.00317.x

60. Wonglimpiyarat, J. (2015). Challenges of SMEs innovation and entrepreneurial financing. World Journal of Entrepreneurship, Management and Sustainable Development, 11 (4), 295-311. https:// doi.org/10.1108/WJEMSD-04-2015-0019

61. Xu, X., Wang, Y., \& Tao, L. (2019). Comprehensive evaluation of sustainable development of regional construction industry in China. Journal of Cleaner Production, 211, 1078-1087. https:// doi.org/10.1016/j.jclepro.2018.11.248

62. Xu, Z., \& Liao, H. (2014). Intuitionistic Fuzzy Analytic Hierarchy Process. IEEE transactions on fuгzy systems, 22 (4), 749-761. https://doi.org/10.1109/TFUZZ.2013.2272585

63. Yang, W., Chen, Z., \& Zhang, F. (2017). New group decision-making method in an intuitionistic fuzzy setting based on TOPSIS. Technological and Economic Development of Economy, 23 (3), 441-461. https://doi.org/10.3846/20294913.2015.1072754

64. Ye, J. (2015). An extended TOPSIS method for multiple attribute group decision making based on single-valued neutrosophic linguistic numbers. Journal of Intelligent \& Fuzzy Systems, 28 (1), 247-255. https://doi.org/10.3233/IFS-141295

65. Yuan, M. H., \& Lo, S. L. (2020). Ecosystem services and sustainable development: Perspectives f1 rom the food-energy-water Nexus. Ecosystem Services, 46, 101217. https://doi. $\operatorname{org} /: 10.1016 /$ j.ecoser.2020.101217

66. Zadeh, L. A. (1965). Fuzzy set. Information and control, 8, 338-353. https://doi.org/10.1016/ S0019-9958(65)90241-X

67. Zamani, M., Rabbani, A., Yazdani-Chamzini, A., \& Turskis, Z. (2014). An integrated model for extending brand based on fuzzy ARAS and ANP methods. Journal of Business Economics and Management, 15 (3), 403-423. https://doi.org/10.3846/16111699.2014.923929 
68. Zhang, H., Wang, J., \& Chen, X. (2016). An outranking approach for multi-criteria decisionmaking problems with interval-valued neutrosophic sets. Neural Computing and Applications, 27 (3), 615-627. https://doi.org/10.1007/s00521-015-1882-3

\section{Contact information}

Amir Khalilsanjani

Sharif University of Technology

Management Faculty

Business Administration

Iran

E-mail:amirsanjani@pardis.sharif.edu

ORCID:0000-0002-8066-1559

Jonas Saparauskas, Ph.D.

Vilnius Gediminas Technical University

Faculty of Civil Engineering

Department of Construction Management and Real Estate

Lithuania

E-mail:jonas.saparauskas@vilniustech.lt

ORCID: 0000-0003-3685-7754

Abdolreza Yazdani-Chamzini

Islamic Azad University

South Tehran Branch

Young Researchers and Elite Club

Iran

E-mail:abdalrezaych@gmail.com

ORCID:0000-0001-5594-7726

Zenonas Turskis

Vilnius Gediminas Technical University

Faculty of Civil Engineering

Institute of Sustainable Construction

Lithuania

E-mail: zenonas.turskis@vilniustech.lt

ORCID: 0000-0002-5835-9388

Alireza Feyzbakhsh

Sharif University of Technology

Graduate School of Management and Economics

Department of Management

Iran

E-mail: alireza_feyz@sharif.edu

ORCID: 0000-0001-9762-612X 